EDWARD B. POULTON, D.Sc., F.R.S.

\title{
Two specially significant examples of insect mimicry.
}

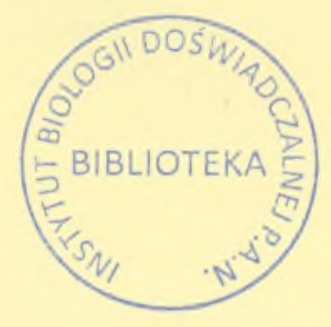

From the Transactions of the Entomological Society of London, VOL. LXXIX, JULY IO, $193 \mathrm{I}$. 
rcin.org.pl 
By Edward B. Poultow, D.Sc., F.R.S., Fellow of Jesus College, Oxford, and Hope Professor of Zoology in the University.

[Read 6th May, 1931.]

Plates XIV, XV.

MinETIC resemblance independent of affinity is of course well known, especially among the Lepidoptera with striking colours and patterns ; indeed, "There is no end to it," as the late Osbert Salvin once said to the writer. Many students of evolution, both naturalists and followers of other sciences, believe that these resemblances and the circumstances in which they are manifested can only be understood in the light of the Darwin-Wallace hypothesis of Natural Selection. Others, unconvinced by this interpretation and having, so far as I am aware, no other to offer, await some unknown solution which appears to be brought no nearer by an ever-accumulating mass of fresh observations. It therefore occurred to me that an illustrated account of two remarkable examples which point with quite exceptional clearness to an evolutionary history based on selection might perhaps induce some of our agnostic friends to assume a more positive and hopeful attitude. The two coloured plates, essential in support of the evidence, and in order to carry conviction, have been made possible by a grant from the Fund for Promoting the Study of Organic and Social Evolution, presented to Oxford University by my old friend Professor James Mark Baldwin. I wish also to thank Miss O. F. Tassart for the care and skill with which she prepared the excellent drawings and the engravers for the successful reproductions.

A fealure in the mimelic resemblance of Papilio laglaizei, Depuiset, to the Uraniid moth Alcidis agathyrsus, Kirsch.-I owe the opportunity of bringing forward this striking instance, to the kindness of Dr. Karl Jordan who has so often given me much help in my work. The Uraniid moth Alcidlis agathyrsus and its mimic Papilio laglaizei inhabit New Guinea and Waiget, while in Aru the butterfly, originally named from one of these islands as alcidinus by Butler, is said by him to be " an exact copy on the upper surface of Alcidis aruus of Felder." * Dr. Jordan informs me that the British Museum specimen of alcidinus from Aru does not differ from the New Guinea laglaizei, although the Alcidis is slightly different from agathyisus.

Dr. Jordan, in Seitz, 1927, 9: Indo-Australian Rhopalocera, 46, 47, places the laglaizei Group of Swallowtails before the Groups of anastus and demoleus and immediately after that of castor, all belonging to Section $\mathrm{B}$, the Fluted Papilios, to which P. machaon belongs. According to A. S. Meek, on whom Dr. Jordan has relied for information, laglaizei is not rare at the S.E. extremity of British New Guinea, but uncommon elsewhere throughout the island. The Alcidis model and butterfly mimic "fly together round the tops of trees, but the Uranid is much commoner than the Papilio." Both, taken on the same day, 9 August, 1912, at Waigani, Milne Bay, S.E. New Guinea, were kindly presented to the Oxford University Collection by Mr. G. M. Carson-

* 1883, Ann. Mag. Nat. Hist., (5) $11: 423$.

TRANS. ENT. SOC. LOND. 79. PART II. (JULY 1931.) 
part of a long series of valuable specimens from the same area. Other examples of model and mimic taken by Native collectors, probably on the E. side of Geelvink Bay, Dutch New Guinea, were kindly presented by Lord Rothschild.

Coming now to the mimetic resemblance between the butterfly and moth, the simple upper surface pattern, similar in both insects, is made up of beautiful, pale greenish blue, iridescent markings on a black ground, the short, broadbased "tail" of the hind-wing being whitish blue. Thus, as Dr. Jordan states, "the resemblance to Alcidis agathyrsus is surprisingly faithful on the upper surface," while, as may be seen by comparing figs. 1 and 2 on Plate XIV, "the under surface differs considerably from that of the model, but bears a usually very conspicuous orange spot which corresponds to the orange-coloured underside of the abdomen of Alcidis." This is the essential feature, so well illustrated on Plate XIV, and pointing so clearly to an evolution due to selection by enemies whose actions were determined by the sense of sight. Looking at the model as shown in fig. 1 we may feel confident that, in the resting position, the moth hangs, probably from a twig, with drooping wings so that the orange under surface of the abdomen is higher than any part of the wing-pattern and, strongly contrasted with all others, forms by far the most conspicuous and easily remembered marking on the insect-a typical aposeme. Now if we suppose, as some have done, that mimetic resemblance is brought about by model and mimic reaching independently the same stage of development in the feature which exhibits the likeness, then, quite apart from the difficulty imposed by the immense difference between the two insects, it is obvious that such an interpretation implies that the orange patch should have appeared on the abdomen of the butterfly and not in two halves on the hind-wings. But if it had so appeared it would have been invisible when the abdomen is enclosed between the two hind-wing grooves, as it is in the Papilios. These grooves are clearly shown in fig. 2 , representing the hind-wings strained apart-a position unnatural in life. In fig. 3 they are shown with the grooves closed over the body and the two halves of the orange patch united. This is probably the appearance in the natural resting position, hanging with drooping wings like the model. It is much to be hoped that some naturalist who has the opportunity will test these conclusions by observing the positions during prolonged rest of both model and mimic. It appears to be probable that if the wings of the resting Papilio hung vertically, a chink would open between the hindwings, and the orange patch would divide. I think it is likely, however, that the mimetic resemblance has been increased by the butterfly assuming when at rest the more moth-like position of drooping and not vertically hanging wings.

It is interesting to find that the only other species in the laglaizei GroupPapilio toboroi, Ribbe, from Bougainville, Solomon Islands, and rather common in low situations in the interior, resembles, in the absence of an Alcidis, a Geometrid moth, Dysphania pilosa, Butler, which is apparently common in the island, and "in spite of its smaller size, bears quite the same aspect as the Papilio" (Ibid., p. 47). The species of Dysphania are conspicuous day-flying moths well known to be mimicked in other localities.

It should be added that similar although less striking methods of resemblance to models are found in other species. Thus, among the especially distasteful and conspicuous Papilios of the Aristolochia (or Pharmacophagus) Section A, certain species with red markings on the body are mimicked by Papilios of another Section (the Kite Swallowtails, or Cosmodesmus) and by certain 
Pierines (Euterpe), with red on the part of the hind-wings which covers the dark body and thus simulates a red body-marking, also often with red on the extreme base of one or both wings which is close to the body.

False cocoons of parasites spun or otherwise formed by caterpillars outside their own cocoons. - Our knowledge of these most remarkable adaptations is almost entirely due to'the acute observations conducted by Dr. W. A. Lamborn, O.B.E., when residing at Oni, about 70 miles E. of Lagos. The most interesting of them, represented, natural size, on Plate XV, was described in Proc. Ent. Soc. Lond., 1911: xcv, ci, and 1930, 5: 13. In fig. 1, eight reddish cocoons of a Bombycid moth, Norasuma kolga, Druce, are represented on the under surface of a leaf. Before constructing its cocoon the caterpillar spins a loose web bearing several oval masses of yellow silk which closely resemble the cocoons spun by parasitic larvae of BRACONIDAE, after devouring their host and making their way to the surface. Within this network the Bombycid caterpillar then spins its own dense cocoon and reddens it, probably by means of a nitrogenous fluid excreted by the Malpighian tubules and discharged from the anus-another example of the advantageous use of a waste product; for the little yellow masses stand out far more conspicuously because of their reddish background. A female and three males which emerged from four of the cocoons are represented in figs. 2, 3, 5 , and 6 , respectively, also a female Ichneumonid parasite in fig. 4. This insect, determined by Mr. D. S. Wilkinson* as Mesostenus basimacula, Cam., had developed from a solitary larva which, after devouring its host, pupated within one of the reddish cocoons and not on the surface after the manner of the Braconidae. It has been suggested that these false cocoons are adapted to deceive the female parasite and thus prevent her from ovipositing in the Bombycid caterpillar or pupa. This interpretation is most improbable because such females are guided by other senses as well as by sight, if indeed sight is employed at all for this purpose. Furthermore, the parasitic larvae which emerged and spun yellow cocoons like the pretence ones represented on Plate $\mathrm{XV}$, would have been hatched from eggs deposited at a much earlier period and probably far back in the life of the Bombycid caterpillar.

The tough wall of a Braconid cocoon, together with the small size of the enclosed larva or pupa, probably explains the meaning of the bright yellow colour as a warning to insectivorous Vertebrates that it will be difficult to reach the food within and that when reached it will be very scanty. A few experiments, perhaps a single one, would teach two lessons-(1) that a cocoon bearing these parasites in their silken cases only encloses a shrunken skin or empty shell and is not worth opening, (2) that the parasitic cocoons are also unworthy of attention. The aposematic conspicuousness of the latter is advantageous to the Bracons because enemies are all the more readily discouraged from making attempts which would incidentally lead to the destruction of some of them. Hence the obvious advantages conferred by false cocoons of parasites when mistaken for real ones.

The above line of reasoning is supported by observations which prove that birds are quick to appreciate the difference between objects which may or may not provide food or may provide different qualities of food. This is well shown by the fact that they will open " bullet galls" which contain the insect, but save themselves the trouble of opening empty ones, guided by the small hole of exit or by some difference in their vibration when tapped with the beak (Ibid., $1928,3: 50-52 ; 1929,4: 10)$. Such observations teach us that birds have

* Bull. Ent. Res., 21 : 284. 
to work for their living and cannot afford to waste time and effort upon worthless objects. The behaviour of birds, as well as mammals and reptiles, towards distasteful insects with warning colours also proves that their reactions are such as are likely to benefit the relatively few species which construct false parasitic cocoons.

The interpretation here offered is also strongly supported by the fact that false cocoons are made in an entirely different manner by the larvae of certain other moths. The cocoon of the IV. African Deilemera antinorii, Oberth. (CAllimorphidae), was observed by Dr. Lamborn to be covered by numbers of little creamy-white or yellowish spheres which so forcibly suggested a mass of Braconid cocoons, that he was at first deceived. Later on he observed that the apparent cocoons were really little spheres of bubbles ejected one at a time per anum, by the larva while it was spinning its cocoon, but ccasing work during the actual passing of a sphere. When two or three have accumulated "the larva turns round, weaves a few turns of silk round one and drags it away to the required position. . . . It then fixes it by a few further turns of silk, and then removes the remaining spheres one by one in a similar way. . . . I think the silk serves as a handle" (1911, Proc. Ent. Soc. Lond., 1911 : xcvi, xcvii ; see also xlvi, lv; 1913 : v).

The late Mr. G. F. Leigh, of Durban, also observed the same procedure in the E. African D. leuconoe, Hopff., and was at first similarly deceived, for, in his own words, "When I first bred this species I actually threw away three or four cocoons of the first lot, thinking that Ichneumonid [Braconid] parasites had emerged from the larvae." He also observed that the larva, like that of the Bombycid $N$. kolga, was attacked by a true Ichneumonid parasite; also that another Deilemera, which he observed in the Comoro Islands, similarly ejects false Bracon cocoons (Ibid., 1911: xcvii, xcviii).

Similar but much smaller bodies, almost certainly passed by the anus, are found on the cocoons of the 'Tineid genus Marmara, as described, with references to the original records, by the late Mr.J.H.Durrant (Ibid., xcviii, xcix; 1912 : cix).

The most remarkable method of producing the same effect was observed by Mr. E. Ernest Green in the Tineid moth Epicephala chalibacma, Meyr., in Ceylon, and this may turn out to be the method of Marmara. The larva of Epicephala " after weaving a thin silken covering . . . rests for a few moments, and a convulsive movement of the posterior segments is noticeable. Very soon a globular pellet - apparently composed of dried bubbles - is voided whole. The caterpillar then turns round inside the cocoon, rapidly attaches the globule to the roof of the cocoon by a stout silken cord, bites a small hole close to the point of attachment, and pushes the globule and cord up through this aperture. The rent is then quickly repaired. This is followed by another short pause, the evacuation of a second pellet, and a repetition of the previous performance, the second pellet being placed at the opposite extremity of the cocoon, in consequence of the caterpillar having reversed its position in the cocoon. The same movements are continued, until the complete crest of globules is in position. . . The number of pellets probably varies, but-in one cocoon-I have counted more than forty of these little objects " (Ibid., 1912 : cvi-cix). It is interesting to note that these pellets are first produced inside the cocoon, and those of Deilemera and Norasuma outside a loose network which the larva subsequently enters and uses as its cocoon or within which it constructs a new one. The remarkable procedure of Epicephala has also been observed by Prof. T. Bainbrigge Fletcher and described by his Second Assistant, Y. Ramachandra Rao (Ibid., 1913 : xxxviii-xl; see also 1912 : cix, cxxxviii). 


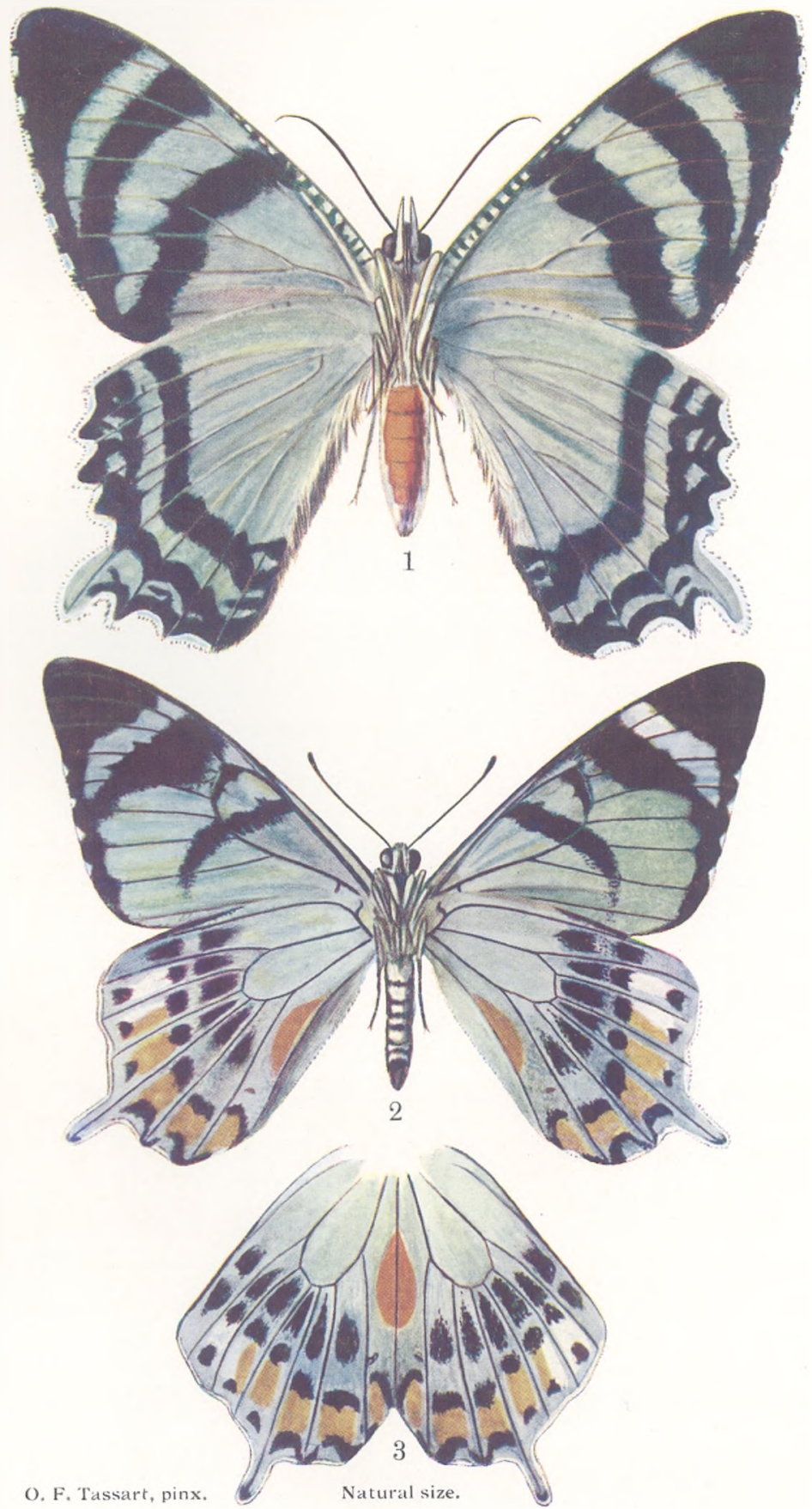

(1) Underside of Model, the Uraniid moth dicialis agathyrsus, with orange patch on abdomen. ('2) Underside of Mimic, Papulsu laslazei, with two orange marks forming a single patch over the abdomen when the hind wings come together (3). lioth model and minic fly together in New Guinea.

rcin.org.pl 


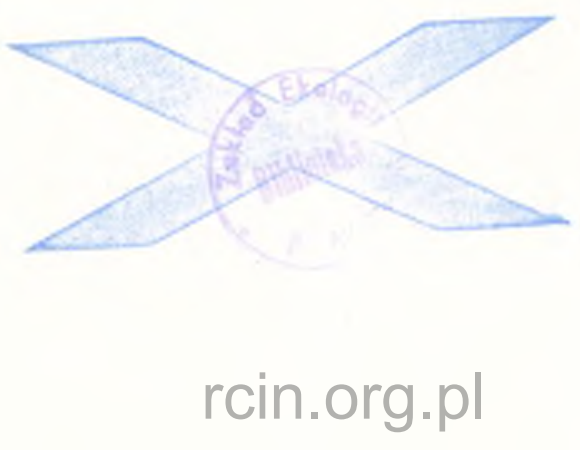




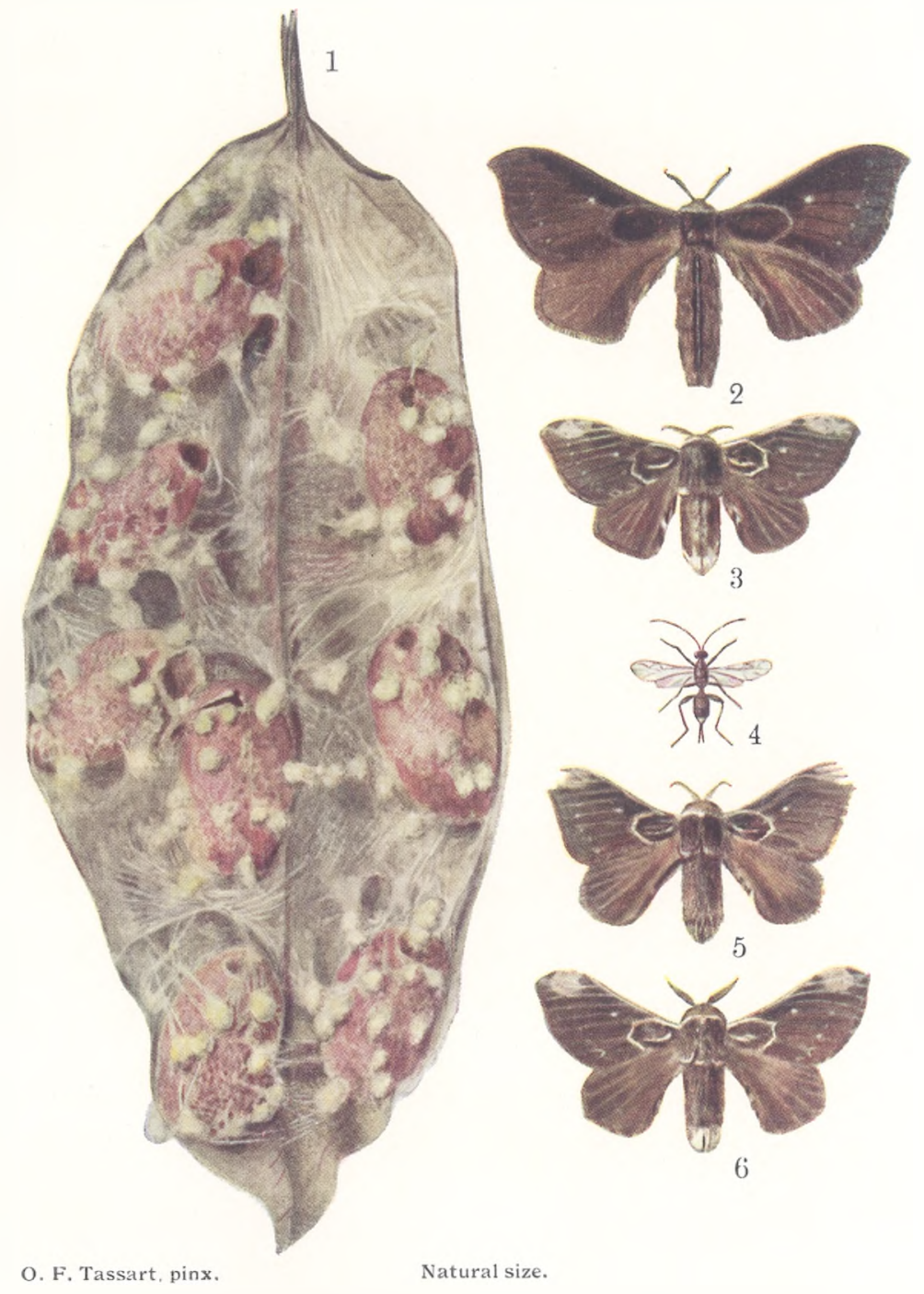

Underside of leaf with 8 cocoons of Bombycid moth Norasuma kolga (1). Yellow masses, spun on a loose net over the reddish cucoons, resemble cocoons of Braconid pardsites. The female moth (2) and males $(3,5,6)$ emerged from 4 red cocoons, an Ichneumonid inot Braconid) parasite (4) from another. W. A. Lamborn, Lagos District, 1912. 


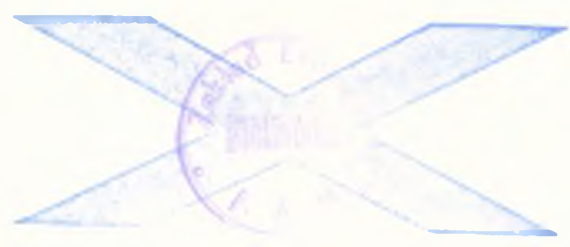

rcin.org.pl 
rcin.org.pl 
rcin.org.pl 